\title{
The Efficacy of Different Modalities Used In the Repair Of Incisional Hernias
}

\author{
${ }^{1}$-Dr.Sudad Salman Ahmed Al-Bassam: FICMS,CABS,IMRCS,FEBS, \\ ${ }^{2}$ Dr.Ahmed Manea Hussein, CABS, ${ }^{3}$ Dr.Osama Mohammed Al-Abid FICMS, \\ FRCS \\ 1- Department Of Surgery, Al-Nahrain Medical College, Baghdad, Iraq \\ 2,3 Department Of Surgery, Al-Imamain Al-Kadhumien Medical City
}

\begin{abstract}
:
Introduction: Incisional hernia is a serious surgical problem and has been reported to occur in 2 to 11 per cent of laparatomy incisions and remain a frequent and serious complication of abdominal surgery. Repair of large abdominal incisional hernias is a difficult surgical problem with recurrence being a common outcome. Major complications which can occur in repair of large incisional hernias include mesh infection and enterocutaneous fistula.
\end{abstract}

The Aim Of The Study: is to evaluate and compare the efficacy of using Primary suture repair and On-lay mesh implantation in the repair of midline incisional hernias.

Patient And Methods: A prospective study done during the period from January 2010 to January 2012 at AlKadhmyia Teaching Hospital in Baghdad. The patients' full data regarding history of risk factors and abdominal surgical history were recorded. Among 76 patients with midline incisional hernia enrolled in this study, 41 patients of them were assigned to On-lay mesh repair and 35 patients to Primary suture repair. These patients were evaluated for 12 months after surgery either by outpatients' clinic visits or phone.

Results: The overall recurrence rate was seen in 12 patients (15.8\%). It was seen in 9 patients (25.7\%) of those who underwent Primary suture repair, while in 3 patients (7.3\%) of those with On-lay mesh repair. In $75 \%$ of patients who developed recurrence, the recurrence occurred after 6 months of Incisional hernia repair. Conclusion: Prosthetic hernia repair gives acceptable recurrence rates and have a good results in comparison to suture repair. The use of prosthetic mesh should be considered for repair of large or recurrent incisional hernias, especially in high risk patients.

\section{Introduction}

Numerous methods of repair have been described - Primary repair in one or two layers, Mayo-type overlap, use of fascia (local or flaps) with suture darns, and the use of fascia with synthetic mesh (Polypropylene or Marlex mesh, Stainless steel, Mersilene or Expanded Polytetrafluoroethylene $)^{(15,17)}$.

Many operative techniques with prosthetic materials have been described on the basis of the anatomic position ${ }^{(19)}$. An excellent method, which has been used, called Rive's Stoppa technique, where mesh was placed between peritoneum and abdominal wall or rectus muscle and posterior rectus sheath ${ }^{(6)}$. The main advantage of On-lay mesh repair it keeps mesh separated from abdominal contents by suturing the mesh to anterior rectus sheath after fascial defect has been closed primarily, therefore avoids adhesions, bowel obstruction, enterocutaneous fistula and erosion of mesh, minimal morbidity and duration of hospital stay is less compared to other prosthetic hernia repair techniques. The main disadvantages are extensive preparation of fascial plane, mesh infection when surgical wound is infected, and need more surgical experience ${ }^{(20,21)}$. Any prosthesis when used in repair of abdominal wall defects can be located in between any two layers of abdominal wall to bridge a defect in the abdominal wall and it may be: 1.Overlay (On-lay) 2.Inlay 3.Underlay 4.Retrorectus 5.Preperitoneal 6.Intermuscular ${ }^{(22)} \mathrm{s}$, as shown in figure: 1 

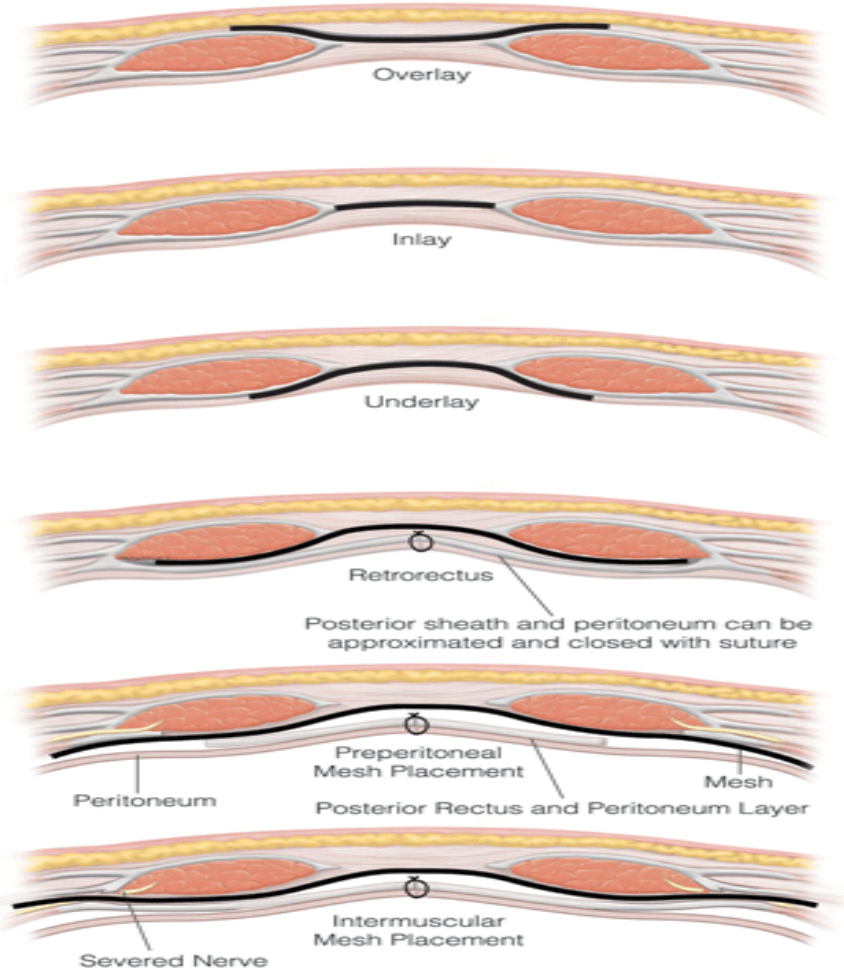

Figure: 1 Sites of mesh placement between layers of abdominal wall in the repair of abdominal wall defect. (22) Mesh repair of incisional hernias showed favorable results regarding hernia recurrence compared to non-mesh repair in several non-randomised trials and in one controlled randomized trial reported on by Luijendijk ${ }^{(23)}$. The latter study proved the superiority of mesh repair over non-mesh or suture repair with regard to recurrence rates ${ }^{(23)}$. Repairs that include the use of mesh to close the defect have better but still high recurrence rates, up to $36 \%{ }^{(10)}$. After repair of recurrent incisional hernias, recurrence rates up to $\mathbf{4 8} \%$ have been reported ${ }^{(24)}$

\section{Patients \& Methods}

Between January 2010 and January 2012, a prospective study was done at Al-Kadhymia Teaching Hospital in Baghdad, were randomly assigned $\mathbf{7 6}$ adult patients scheduled to undergo repair of a midline incisional hernia; whether to Primary (continuous polypropylene) suture repair (35 patients) or On-lay mesh repair (41 patients). Exclusion criteria were the presence of more than one hernia, signs of infection, prior hernia repair with mesh, and plan to repair the hernia as part of another intraabdominal procedure. Those who were older than 60 years old or with BMI (Body Mass Index) more than $40 \mathrm{~kg} / \mathrm{m}^{2}$ were also excluded from the study. The patients could be enrolled only once.The patients' full data regarding history of risk factors and abdominal surgical history were recorded. Obesity was defined as a BMI (the weight in kilograms divided by the square of the height in meters) of at least 30. The preoperative length or width of the fascial defect was also recorded. Factors related to the operation, including the surgical technique and the presence or absence of hematoma, dehiscence, and infection, were also analyzed. Wound infection was defined by the discharge of pus from the wound. Two types of repair of incisional hernia were used (Primary suture repair and On-lay mesh repair); all operations were performed under general anesthesia. After skin preparation and draping, the cutaneous scar was excised and the hernia sac dissected, it is then formally opened and the contents are reduced. Adherent omentum and bowel have to be freed by dissection before the mouth of the sac can be defined. The sac was opened only if there was a definite history of obstruction or if the sac was irreducible. The rectus sheath was clearly exposed around the circumference of the defect ${ }^{(5)}$.

\section{Primary suture repair}

In the patients assigned to undergo Primary suture repair, first the peritoneum were approximated with absorbable sutures and then the two edges of the fascia were approximated in the midline, usually with a continuous non-absorbable sutures (polypropylene no.1): A second layer of closure (Keel) and (Darn) repair was used. When necessary, tension-relaxing incisions may be required and should be placed well laterally ${ }^{(5)}$. 


\section{On-lay mesh implantation}

First the peritoneum were approximated with absorbable sutures and then the two edges of the fascia were approximated in the midline, usually with a continuous non-absorbable sutures (polypropylene no.1). A large sheet of Polypropylene mesh was implanted subcutaneously in direct contact to rectus sheath. The prosthesis extending $($ 4-6 $\mathrm{cm})$ beyond the defect all around and was maintained by circumferential continuous or interrupted nylon suture transfixing the mesh.Careful haemostsis and meticulous asepsis are essential during these operations. Postoperative collections of serum can be removed by drainage using plastic tubing that leads, via skin punctures lateral to the wound, into closed suction drainage bottles (e.g. RediVac). Skin was closed by either interrupted sutures or subcuticular suture.Post-operative care, gastric decompression and intravenous fluids are employed, and nothing by mouth allowed until the bowels have functioned. Early ambulation and gentle physical exercise is to be encouraged. The patient should not resume strenuous exercise for several months. The patients were evaluated for $\mathbf{1 2}$ months after surgery either by outpatients' clinic visits or phone. Patients recorded their pain according to Numerical Rating Scale (NRS) in which patients were instructed to choose a number from $\mathbf{0}$ to $\mathbf{1 0}$ that best describes their current pain. $\mathbf{0}$ would mean 'No pain' and $\mathbf{1 0}$ would mean 'Worst possible pain'. Those who gave a score equal or less than $\mathbf{6}$ (mild-moderate) have a pain treated by simple oral analgesia while those with a score more than $\mathbf{6}$ (severe) were in need of more powerful injectable analgesia. Wound infection was defined by the discharge of pus from the wound. Patients' awareness of any recurrence of the hernia and concern about the scar were noted. The scar was examined for recurrence of hernia, the examination included palpation while the patient was in the supine position with legs extended and raised. Recurrence was defined as any fascial defect that was palpable or detected by ultrasound examination. Ultrasound examinations were performed to determine size of fascial defect.

\section{Chi - square test $\left(\mathrm{X}^{2}\right)$ and fisher exact test:}

Chi - square test (X2) and fisher exact test were applied with a level of the $\mathrm{P}$ value $<0.05$ being set for statistically significant relationship.

\section{Results}

Among the 76 patients enrolled in the study, 47 patients $(61.8 \%)$ were females and 29 patients (38.2\%) were males, giving M:F ratio of (1:1.6). 35 patients $(\mathbf{4 6 . 1 \%})$ were assigned to primary suture repair and 41 patients $(\mathbf{5 3 . 9 \%})$ were assigned to On-lay mesh repair. The age of patients ranged from 23-60 year-old, 34 patients $(\mathbf{4 4 . 7 \%})$ were below 40 years (mean $32.4 \pm 5)$ and 42 patients $(\mathbf{5 5 . 3 \%})$ above 40 years (mean $51.4 \pm$ 4)The BMI ranged from $\mathbf{2 1 . 0 - 3 9 . 7} \mathrm{kg} / \mathrm{m}^{2}, \mathbf{2 5}$ patients $(\mathbf{3 2 . 9 \%})$ were equal or less than $30 \mathrm{~kg} / \mathrm{m}^{2}$ BMI (mean 23.5 $\pm \mathbf{1 . 5}$ ) and 51 patients $(\mathbf{6 7 . 1 \%})$ were more than $30 \mathrm{~kg} / \mathrm{m}^{2}$ BMI (mean $35.8 \pm \mathbf{1 . 4}$ ) There were 33 patients $(\mathbf{4 3 . 4 \%})$ with length or width of fascial defect equal or less than $5 \mathrm{~cm}$ (mean $3.75 \pm 0.9$ ), while 43 patients $(\mathbf{5 6 . 6 \%})$ with fascial defect of more than $5 \mathrm{~cm}$ (mean $7.96 \pm \mathbf{1 . 4})$. There were 20 patients $(\mathbf{2 6 . 3 \%})$ with clean previous operations, 18 patients $(\mathbf{2 3 . 6 \%})$ with clean-contaminated previous operations and 38 patients $(\mathbf{4 9 . 1 \% )}$ with contaminated previous operations.

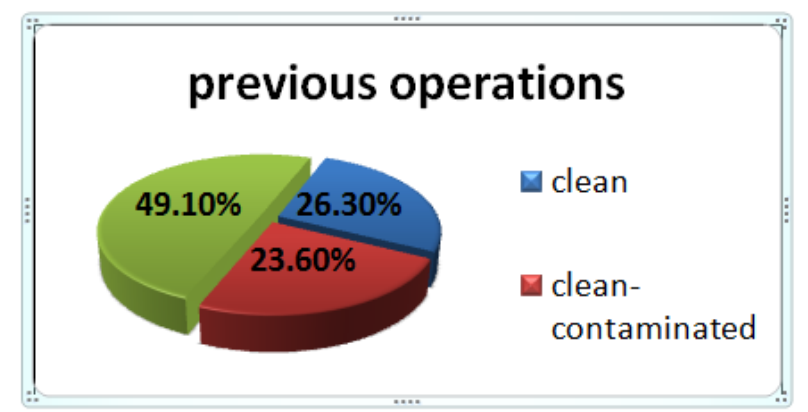

Figure: 2 Distribution of patients according to type of previous operations.

Concomitant medical diseases seen in 43 patients (56.6\%); including diabetes mellitus in 16 patients (21.1\%), hypertension in 14 patients (18.4\%), malignancies in 3 patients (3.9\%), steroid therapy in 4 patients $\mathbf{( 5 . 3 \%}$ ), and obstructive airway disease in 6 patients $\mathbf{( 7 . 9 \% )}$. The mean follow up time for all patients was $(\mathbf{9 . 5}$ months) ranging from (1-12 months).

The mean operative time was (82minutes) for primary suture repair and (73 minutes) for on-lay mesh repair.8 patients gave a pain score $>6$ in the study, 6 patients (14.6\%) with On-lay mesh repair and 2 patients (5.7\%) with Primary suture. Other forms of complications are clarified in [Table: 6] 
Table: 6 Distribution of patients according to post-operative complications.

\begin{tabular}{|l|l|l|l|l|l|l|}
\cline { 2 - 7 } \multicolumn{1}{c|}{} & \multicolumn{3}{c|}{ TYPE OF REPAIR } & \multicolumn{3}{c|}{ Total } \\
\cline { 2 - 8 } \multicolumn{1}{c|}{} & \multicolumn{2}{c|}{ Primary suture } & \multicolumn{2}{c|}{ On-lay mesh } & No. & $\%$ \\
\hline COMPLICATIONS & No. & $\%$ & No. & 9.8 & 6 & 7.9 \\
\hline Wound infection & 2 & 5.7 & 4 & 12.2 & 6 & 7.9 \\
\hline Seroma & 1 & 1.3 & 5 & 14.6 & 8 & 10.5 \\
\hline Pain & 2 & 5.7 & 6 & 7.3 & 4 & 5.3 \\
\hline Sinus & 1 & 1.3 & 3 & 7.3 & 12 & 15.8 \\
\hline Recurrence & 9 & 25.7 & 3 & 51.2 & 36 & 47.4 \\
\hline Total & 15 & 42.8 & 21 & & & \\
\hline
\end{tabular}

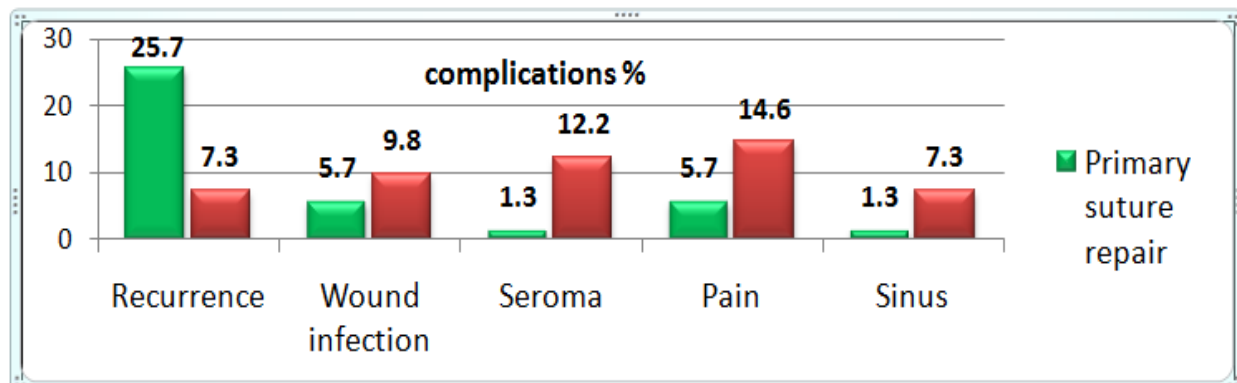

Fig: 3 Percentage of patients according to post-operative complications.

The inhospital stay of this study was ranging from $\mathbf{2 - 5}$ days, with a mean of $\mathbf{3 . 5}$ days. The overall recurrence rate was seen in $\mathbf{1 2}$ patients $\mathbf{( 1 5 . 8 \% )}$. Recurrence was significant regarding type of repair $(\mathrm{P}$ value $=$ 0.028). It was seen in 9 patients $(\mathbf{2 5 . 7 \%})$ of those who underwent primary suture repair, compared to 3 patients $\mathbf{( 7 . 3 \% )}$ of those with On-lay mesh repair [Figure: 4].

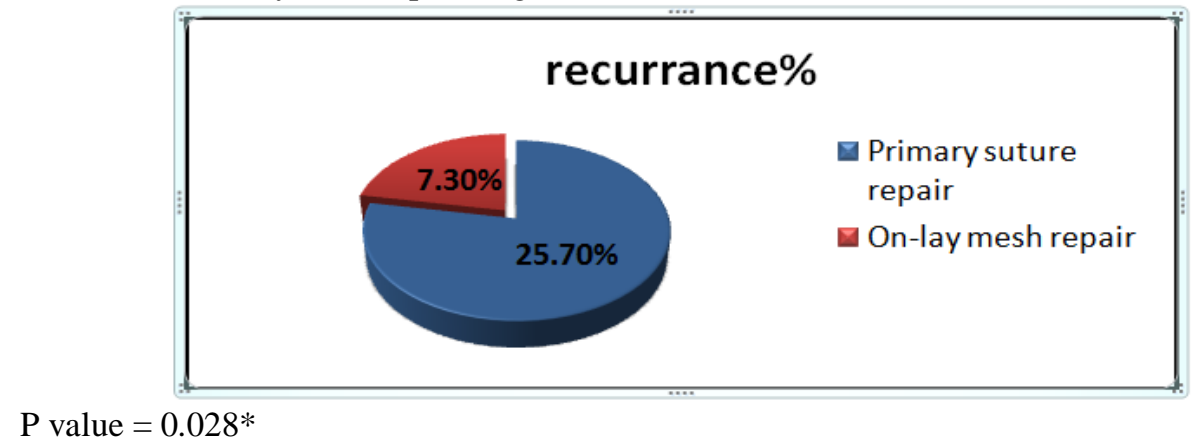

Fig: 4 Recurrence rates following repair of incisional hernia.

Of those 12 patients who developed recurrence; 3 of them $\mathbf{2 5 \%}$ ) developed recurrence in first six months after operation, while 9 patients (75\%) developed recurrence after six months of operation.In this study although recurrence was more common in female patients with a rate of (17.0\%), in patients older than 40 years $\mathbf{( 1 6 . 6 \% )}$, in patients with BMI $>30 \mathrm{~kg} / \mathrm{m}^{2} \mathbf{( 1 6 . 7 \% )}$, in patients with a fascial defect $>\mathbf{5} \mathrm{cm}(\mathbf{1 6 . 3 \%})$, and in patients with concomitant diseases $\mathbf{( 1 8 . 6 \%}$ ) but it was not significant for these risk factors ( $\mathrm{P}$ value $>0.05)$.

Number and percentage of patients who developed recurrence in regard to other risk factors following primary suture repair and on-lay mesh repair were clarified in [Table: 8, Figure: 5].

Table: 8 No. and percentage of Recurrence in regard to risk factors.

\begin{tabular}{|c|c|c|c|c|c|c|}
\hline \multirow{2}{*}{\multicolumn{2}{|c|}{ RISK FACTORS }} & \multicolumn{2}{|c|}{ RECURRENCE } & \multicolumn{2}{|c|}{ Total } & \multirow[b]{2}{*}{$\mathrm{P}$ value } \\
\hline & & \multirow{2}{*}{$\begin{array}{c}\begin{array}{c}\text { Primary } \\
\text { suture }\end{array} \\
6(26.1 \%)\end{array}$} & \multirow{2}{*}{$\begin{array}{l}\begin{array}{c}\text { On-lay } \\
\text { mesh }\end{array} \\
2(8.3 \%)\end{array}$} & \multirow{2}{*}{$\begin{array}{l}\mathrm{N} \\
\text { o. } \\
8\end{array}$} & \multirow{2}{*}{$\frac{\%}{17.0}$} & \\
\hline \multirow[b]{2}{*}{ gender } & Female & & & & & \multirow{2}{*}{0.745} \\
\hline & Male & $3(25.0 \%)$ & $1(5.8 \%)$ & 4 & 13.8 & \\
\hline \multirow{2}{*}{ Age (years) } & $<40$ & $4(26.6 \%)$ & $1(5.3 \%)$ & 5 & 14.7 & \multirow{2}{*}{0.636} \\
\hline & $>40$ & $5(25.0 \%)$ & $2(9.1 \%)$ & 7 & 16.6 & \\
\hline \multirow{2}{*}{$\begin{array}{r}\text { BMI } \\
\left(\mathrm{kg} / \mathrm{m}^{2}\right)\end{array}$} & $<30$ & $3(21.4 \%)$ & $1(7.1 \%)$ & 4 & 14.2 & \multirow{2}{*}{0.763} \\
\hline & $>30$ & $6(28.6 \%)$ & $2(7.4 \%)$ & 8 & 16.7 & \\
\hline \multirow{2}{*}{$\begin{array}{r}\text { Fascial } \\
\text { defect }(\mathrm{cm})\end{array}$} & $<5$ & $4(23.5 \%)$ & $1(6.2 \%)$ & 5 & 15.1 & \multirow{2}{*}{0.636} \\
\hline & $>5$ & $5(27.7 \%)$ & $2(8.0 \%)$ & 7 & 16.3 & \\
\hline \multirow{2}{*}{$\begin{array}{l}\text { Concomitan } \\
\text { t diseases }\end{array}$} & Yes & $6(42.8 \%)$ & $2(6.9 \%)$ & 8 & 18.6 & \multirow{2}{*}{0.745} \\
\hline & No & $3(14.2 \%)$ & $1(8.3 \%)$ & 4 & 12.1 & \\
\hline
\end{tabular}

Fisher exact test was done 


\section{Discussion}

Ventral abdominal wall hernias represent a common complication after abdominal surgeries with an incidence of approximately $\mathbf{2 - 1 1 \%}$. Traditionally, ventral hernia repair has been associated with a high recurrence rate, until the implementation of tension-free repair with prosthesis ${ }^{(28)}$. Incisional hernias show preponderance in female, constitute $\mathbf{( 6 1 . 8 \% )}$ ) of the total number of patients of this study, giving a M:F ratio of (1:1.62) which is higher than (0.8:1) M:F ratio of (H.S. Khaira; et al. 2001) ${ }^{(26)}$, and (1:1.5) M:F ratio seen by (Roland W. Luijendijk) ${ }^{(29)}$. This can be explained by that female in our society were subjected to more conditions associated with increase intra-abdominal pressure in the early post laparotomy period like pregnancy and the less muscle strength they have than males. The incidence of Incisional hernias in this study was found to raise with the increase of patients' age over $\mathbf{4 0}$ years old $(\mathbf{5 5 . 3 \%})$ and with the increase in BMI more than $\mathbf{3 0}$ $\mathrm{kg} / \mathrm{m}^{2}(\mathbf{6 7 . 1 \%})$, which was statistically not significant ( $\mathrm{P}$ value $=0.761$ and 0.459 respectively). In addition, although hernia size is often considered a risk factor for incisional hernia we did not find this to be the case in this study $(\mathrm{P}$ value $=0.308)$ and this does not agree with the predisposing factors described by (Rady Saad \& Saleh Shaheen $)^{(13)}$ and (San Pio JR) ${ }^{(14)}$ In this study concomitant diseases seen less frequently, hypertension was $\mathbf{( 1 8 . 4 \% )}$ and chronic bronchitis was $\mathbf{( 7 . 9 \% )}$ while they were (32\%) and $\mathbf{( 2 6 \% )}$ respectively in (H.S. Khaira; et al. 2001) ${ }^{(26)}$, except for diabetes mellitus which had been seen in (21.1\%) of patients in comparison to (14\%) in (H.S. Khaira; et al. 2001) ${ }^{(26)}$.Incisional hernias were more frequently seen in patients with contaminated

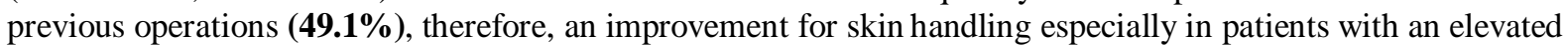
BMI or gross contamination will led to decreased seroma formation and infections in the immediate postoperative period.There was a higher post-operative complication rates; regarding wound infection which was (7.9\%) in comparison with (H.S. Khaira; et al. 2001) ${ }^{(26)}$, Roland W. Luijendijk; et al $200{ }^{(29)}$, and M. Petrousjka van den Tol; et al $2000{ }^{(4)}$ which was $(\mathbf{3 \%}, \mathbf{3 \%}$, and $\mathbf{4 \%})$ respectively. Seroma was $(\mathbf{7 . 9 \%})$ in this study which is also higher than $\mathbf{( 4 . 8 \% )}$ in (Roland W. Luijendijk; et al 2000) ${ }^{(29)}$, and (M. Petrousjka van den Tol; et al 2000) ${ }^{(4)}$. Sinus had been occur in (5.3\%) while in Roland W. Luijendijk; et al 2000 it was $\mathbf{( 1 . 2 \% )}$ (29). This may be due to excessive handling of the skin, especially in patients with an elevated BMI and wide undermining of the skin to release it from underlying fascia will disrupt the perforator blood flow to the midline abdominal skin, thereby contributing to wound complications in these patients ${ }^{(33)}$.Wound complications rates (apart from recurrence) were relatively higher in On-lay mesh implantation way of repair which had been explained by the excessive dissection and tissue trauma and the mesh contact with the subcutaneous fat cause an increase in fluid extravasations and also more damage to blood supply, all these features increase liability for seroma formation and skin infection ${ }^{(4,26,29)}$. Severe pain was seen in $\mathbf{1 4 . 6 \%}$ of On-lay mesh repair in comparison to 5.6\% of patients with Primary suture repair in this study. None of the published studies concentrate on analgesia requirements. We found increased requirement of analgesia in the larger hernias and in those with On-lay mesh repair.

\section{Recurrance}

The recurrence rate in the present study was (25.7\%) for Primary suture repair and (7.3\%) for On-lay mesh repair which is lower than the recurrence rate of Trupka AW et al 1997 [which was (30\%) for primary repair and (15\%) for mesh repair] ${ }^{(30)}$ and Langer $\mathrm{C}$ et al 2003 [which they have a recurrence rate ranging from $\mathbf{( 6 3 \% )}$ ) for primary repair and (32\%) for mesh repair] ${ }^{(25)}$. This may be explained by the larger sample (205 and 432 patients' respectively) and the longer duration of the study ( $\mathbf{8}$ and 25 years respectively) they have.Most of recurrences occurred after 6 months of operation (25\% before 6 months and $75 \%$ after 6 months of operation) and this is agreed with what had been found by (Leber GE; Grb JL; Alexander AI; Reed WP) ${ }^{(16)}$, in which $31.5 \%$ of all incisional hernias developed in the first 6 months after the operation. This may be due to shorter time of follow up.Recurrence in regard to gender was not significant $(\mathrm{P}$ value $=0.745)$. It was seen in $\mathbf{2 6 . 1 \%}$ ) of females underwent Primary suture repair and in $\mathbf{( 8 . 3 \% )}$ of females underwent On-lay repair. While males developed recurrence in $\mathbf{2 5 . 0 \%}$ ) in Primary suture repair and $\mathbf{5 . 8 \%}$ ) in On-lay mesh repair. In addition patients older than 40 years old have a higher recurrence rate (16.6\%) than those younger than 40 years $(\mathbf{1 4 . 7 \%})$ and this agreed when compared to Roland W. Luijendijk; et al $200{ }^{(29)}(\mathbf{4 2 \%}$ and $\mathbf{3 2 \%}$ respectively), but in this study, age was not a significant risk factors for development of recurrence ( $\mathrm{P}$ value $=0.636$ ). We did not find any significant differences ( $\mathrm{P}$ value $=0.636$ ) between those who had fascial defect more or less than $\mathbf{5} \mathrm{cm}$, although, The recurrence rate of this study in regard to fascial defects was seen in $\mathbf{7}$ patients $\mathbf{( 1 6 . 3 \%}$ ) with defects more than $\mathbf{5} \mathrm{cm}$, while it was seen in $\mathbf{5}$ patients $(\mathbf{1 5 . 1 \%})$ for a fascial defect less than $\mathbf{5} \mathrm{cm}$, these rates does not agreed to recurrence rates found by Roland W. Luijendijk; et al $2000{ }^{(29)}$ which was $(\mathbf{1 3 \%})$ and $(\mathbf{4 3 \%})$ for hernias less or more than $5 \mathrm{~cm}$, respectively, which was also not significant $(\mathrm{P}$ value $=0.30)$ by Roland W. Luijendijk; et al $2000{ }^{(29)}$. The incidence of recurrence was more in patients with fascial defect more than $5 \mathbf{c m}$ underwent Primary suture repair (5 patients, $\mathbf{2 7 . 7 \%}$ ) than those underwent On-lay mesh repair (2 patients, $\mathbf{8 . 0 \%}$ ). The extent of the decrease in laxity of the tissue surrounding the hernia, which is influenced by retraction of muscle and scarification of tissues, may be more important than the actual size of the fascial defect ${ }^{(32)}$. There was no 
significant difference (P value $=0.763$ ) in recurrence between patients above or below $\mathbf{3 0} \mathrm{kg} / \mathrm{m}^{2}$ BMI, but the recurrence rate was higher in patients with BMI $>\mathbf{3 0} \mathrm{kg} / \mathrm{m}^{2}$ underwent Primary suture repair (6 patients, $\left.28.6 \%\right)$ than those underwent On-lay mesh repair ( 2 patients, $7.4 \%$ ) and this necessitate the use of prosthetic mesh in high risk patients especially in obesity. Generally, the study shows a significant difference ( $\mathrm{P}$ value $=0.028)$ in the recurrence rate after repair of midline incisional hernia between Primary suture repair (9 patients, $\mathbf{2 5 . 7 \%}$ ) and On-lay mesh repair (3 patients, $\mathbf{7 . 3 \%}$ ). In the technique of Primary suture repair of incisional hernias, the edges of the defect are brought together, which may lead to excessive tension and subsequent wound dehiscence or incisional herniation as a result of tissue ischemia and the cutting of sutures through the tissues. With prosthetic mesh, defects of any size can be repaired without tension. In addition, polypropylene mesh, by inducing an inflammatory response, sets up scaffolding that, in turn, induces the synthesis of collagen. The inhospital stay of this study was ranging from 2-5 days, with a mean of $\mathbf{3 . 5}$ days which is much shorter than what had been seen by (H.S. Khaira; et al 2001) ${ }^{(26)} ;(\mathbf{6 . 2}$ days) and (6 days) of the (M. Petrousjka van den Tol; et al 2000) ${ }^{(29)}$, this can be explained by that our patients had low incidence of concomitant diseases that need less stay in hospital and to the shortage of the bed capacity of the hospital, especially in the period of the study. Mainly umbilical and incisional hernias corrected using a primary suture repair in an acute setting will result in high recurrence rates, irrespectively of size, especially in incisional hernias ${ }^{(34)}$. Even today; mesh repair is not routinely used in the repair of acute hernias. The most probable explanation for the use of primary suture repair is fear of post-operative wound complications, especially in cases in which small or large bowel is incarcerated in the hernia sac, sometimes even necessitating bowel resection. Our study establishes the superiority of mesh repair over suture repair with regard to the recurrence of hernia.

\section{Conclusion}

The On-lay mesh repair revealed acceptable recurrence rates and have excellent results in comparison to Primary suture repair, although there is relatively more pain interfering for early mobilization.

\section{References}

[1]. Anthony T, Bergen PC, Kim LT, et al: factors effecting recurrence following incisional herniorraphy. World J surg 24:95, 2000

[2]. Gutiérrez de la Pena C; Medina Achirica C; Domínguez-Adame E; Medina Díez J Department of Surgery, General hospital, Jerez, Spain. Primary closure of laparotomies with high risk of incisional hernia using prosthetic material: analysis of usefulness. Hernia. 2003; 7(3):134-6(ISSN: 1265-4906).

[3]. American hernia society, Montgomery medical center: incisional hernia and ventral hernias, 2002.

[4]. M. Petrousjka van den Tol, Diederik C.D. de lange, Marijel M.J. Braaksma, Jan N.M. IJzermans, Roelof U. Boelhouwe, Bas C. de Varies, Marc K.M. Salu, Jack C.J. Wereldsma, Cornelis M.A. Bruijninckx, Johannes Jeekel.

[5]. R.C.G Russell, Normans. Williams and Christopher J.K, abdominal wall incisional hernia, short practice of surgery $25^{\text {th }}$ edition P987-989, 2008.

[6]. Itani KMF, Hur K, Kim LT, et al: comparison of laparoscopic and open repair with mesh for the treatment of ventral incisional hernia: a randomizes trial, arch surg 209:653-658, 2009

[7]. Prismant. Utrecht, the Netherlands: National Medical Registration; 2002.

[8]. DeMaria EJ, Moss JM, Sugerman HJ. Laparoscopic intraperitoneal polytetrafluoroethylene (PTFE) prosthetic patch repair of ventral hernia: prospective comparison to open prefascial polypropylene mesh repair. Surg Endosc. 2000; 14:326-329.

[9]. Read RC, Yoder G. Recent trends in the management of incisional herniation. Arch Surg. 1989; 124:485-488.

[10]. Anthony T, Bergen PC, Kim LT, et al. Factors effecting recurrence following incisional herniorraphy. World J Surg. 2000; 24:95100 .

[11]. Wong SY, Kingsnorth AN. Prevention and surgical management of incisional hernias. Int J Surg Invest. 2001; 3:407-14.

[12]. Van't Riet M, deVos van Steenwijk PJ, Bonjer HJ, Steyerberg EW, Jeekel J. Incisional hernia after repair of wound dehiscence: incidence and risk factors. Ann Surg. 2004; 70:281-6.

[13]. Rady Saad \& Salah Shaheen; abdominal wall and hernia, burst abdomen, Kasr El-Ainy introduction to surgery text book, third edition, volume 2 545-546, 2004.

[14]. San Pio JR; Damsgaard TE; Momsen O; Villadsen I; Larsen J Department of Plastic Surgery, Aarhus University hospital, Aarhus, Denmark. Repair of giant incisional hernias with polypropylene mesh: A retrospective study, Scand J Plast Reconstr Surg Hand Surg. 2003; 37(2):102-6 (ISSN:0284-4311)

[15]. Langer S, Christiansen J. Long-term results after incisional hernia repair. Acta Chir Scand 1985; 151: 217

[16]. Leber GE; Grb JL; Alexander AI; Reed WP Department of surgery, Baystate Medical center o Tufts university School of Medicine, Springfield, Mass 01199, USA. Long-term complications associated with prosthetic repair of incisional hernias. Arch Surg. 1998; 133 (4):378-82 (ISSN: 0004-0010).

[17]. Young D. Repair of epigastric incisional hernia. Br J Surg 1961; 48: 514-16

[18]. Cappelletti M, Attolini G, Gangioni G, Mascherini G, Taddeucci S, Gervino L.U.O. Chirurgia General, USL n.8, Ospedale San Giovanni Valdarno, Arezzo. [the use of mesh in abdominal wall defects] Minerva Chir. 1997 Oct; 52(10):1169-76.

[19]. Ponka, management of incisional hernia (1980).

[20]. Mudge M, Hugher LE. Incisional hernia: A 10-year prospective study of incidence and attitudes. B J Surg 1985; $72: 70$.

[21]. Houch JP, Rypins EB, Saffeb IJ et al.Repair of incisional hernia. Surg Gynaecol Obstet 1989; 167: $397-399$.

[22]. Amid PK, Shulman AG, Lichtenstein IL, Sostrin S, Young J, Hakakha M. Experimental evaluation of a new composite mesh with the selective property of incorporation to the abdominal wall without adhering to the intestine. J Biomed Mater Res 1994; 28:373-5.

[23]. Luijendijk RW, Hop WC, Van den Tol MP, DE Lange DC, Braaksma MM, IJzermans JN, Boelhouwer RU, De Vries BC, Salu MK, Wereldsma JC, Bruijninckx CM, Jeekel J. A comparison of suture repair with mesh repair for incisional hernia. N Engl J Med 2000; $343: 392-8$ 
[24]. Manninen MJ, Lavonius M, Perhoniemi VJ. Results of incisional hernia repair: a retrospective study of 172 unselected hernioplasties. Eur J Surg. 1991:157:29-31.

[25]. Alexander Munro, Kevin Cassar. Repair of incisional hernia. Recent advances in surgery. Ed: Colin Johnson and IrvingTaylor, 27: PP 41-53.

[26]. H.S. KHAIRA, P. LALL, B. HUNTER and J.H. BROWN. Department of surgery, good Hope Hospital NHS Trust, Sutton Coldfield, U.K. repair of incisional hernias J.R.Coll.Surg.Edinb.,Februry 2001, 39-43.

[27]. Kingsnorth A, LeBlanc K. Hernias: inguinal and incisional. Lancet. 2003; 302:1561-71.

[28]. Santora T, Roslyn J. Incisional hernia. Surg Clin North Am. 1993; 73:557-570.

[29]. Roland W. Luijendijk, Wim C.J. Hop, M. Petrousjka van den Tol .A comparison of suture repair with mesh repair for incisional hernia. The new England Journal of medicine - August 10, 2000 -vol. 343, no. 6.

[30]. Trupka A.W., Schweiberer L, Hallfeldt K.K, Waldener H. [management of large abdominal wall hernias with foreign implant materials (Gore-Tex patch)] Zentralbl Chir. 1997; 122(10):879-84.

[31]. Jacobus W.A. burger, MD; Roland W. Luijendijk, PhD; Wim C.J. Hop, Phd; Jens A. halm, MD; Emiel G. G. Verdaasdonk, MD; Johannes Jeekel, $\mathrm{PhD}$. Long-term follow-up of a randomized controlled trial of suture versus mesh repair of incisional hernia posted $01 / 07 / 2005$.

[32]. Luijendijk RW. "Incisional hernia": risk factors, prevention, and repair. (Ph.D. thesis) Rotterdam, the Netherlands: Erasmus University Rotterdam, 2000.

[33]. Maas SM, van Engeland M, Leeksma NG, Bleichrodt RP. A modification of the "components separation" technique for closure of abdominal wall defects in the presence of an enterostomy. J Am Coll Surg. 1999; 189(1):138-140.

[34]. Vrijland WW, Tol MP, Luijendijk RW, Hop WC, Busschbach JJ, Lange DC, Geldere D, Rottier AB, Vegt PA, IJzermans JN, Jeekel J. Randomized clinical trial of non-mesh versus mesh repair of primary inguinal hernia. Br J Surg. 2002; 89(3):293-297. Doi: 10.1046/j.0007-1323.2001.02030. 